\author{
Ruxandra DINULESCU, PhD \\ Email: ruxandra.dinulescu@man.ase.ro \\ Professor Ion SMEUREANU, PhD \\ Email: ion.smeureanu @ csie.ase.ro \\ Professor Cosmin DOBRIN, PhD \\ Email: cdobrin@yahoo.com \\ Professor Ion POPA, PhD \\ Email: ipopa@yahoo.com \\ The Bucharest University of Economic Studies
}

\title{
A STATISTICAL APPROACH FOR IMPROVING THE ROMANIAN PUBLIC HEALTHCARE SYSTEM USING THE LEAN SIX SIGMA METHODOLOGY
}

\begin{abstract}
Abstract: Changes in the Romanian public health system, which happen almost every year, are not always beneficial for the patients. Since consumers' needs should be on the first place, every new development opportunity should take that into account. Evidence from 2017 confirms the fact that the public healthcare system is unable to demonstrate a rapid growth, because there are still many deficiencies, which need to be corrected (waste of financial resources, waste of time, etc.). This suggests a meticulous analysis and a necessary deficiencies' gradual improvement, in order to fundamentally improve the public health system.

Notably, managers from public healthcare institutions should be capable of correctly specify what "quality" means; otherwise, expecting a quality management would be hopeless. We therefore consider that improvement processes must have as a debating point the "patients' voice", what dissatisfies them in addition to their rights about a qualitative public health system.

This paper will analyze, and therefore try to predict, an apparently minor yet important aspect, like the circumstance of expecting in front of the medical room. For this analysis two statistical tools were used - ANOVA analysis and regression analysis.

The results, formed as a linear distribution, demonstrated that the patients' delaying time is influenced by the delay in informational system.

In conclusion, as recommendations, the research is an ongoing study, which will further analyze other possible factors that may influence the patients' waiting.

Keywords: public healthcare system, statistical tools, sustainability, regression analysis , Lean Six Sigma.
\end{abstract}

JEL Classification: I30

DOI: $10.24818 / 18423264 / 52.3 .18 .04$ 
Ruxandra Dinulescu, Ion Smeureanu, Cosmin Dobrin, Ion Popa

\section{Introduction}

The Romanian sanitary system has severe problems that need to be addressed.

Nowadays, people have less trust in the public health system due to its diverse failures. Among different problems found in the healthcare system, we can mention problems like: bureaucracy, patients' waiting time, electronic card system blockings, etc. All these have an impact both on patients, as well as on medical staff.

Hence, due to a tough economic era, people prefer with greater reason to lay on rapid fixes and ad hoc results (George, 2010), even consisting of healing themselves in their households, rather than going to the physicians.

The first step, before trying to define or even manage the level of quality in a healthcare system, is to understand the public healthcare system.

Taken as a general structure, quality identifies to an attribute belonging to a product or a service, however of we identify it with the sanitary domain, this demonstrates unique particularities, associating different approaches (reporting to alternative activity domains), a characteristic that confirms its point also on the matters of the performance's level of quality in the sanitary field (Bass, 2007).

In 2017, Romania was situated on the last position (439 points out of 1000 - in the Healthcare European Index) of a ranking made in an analysis supervised by Health Consumer Powerhouse Company, which copes with comparability between countries' diverse healthcare systems. The report took into consideration 34 countries, Holland continuing to dominate the rank, with a rate of 924 out of 1000 points (see figure 1):

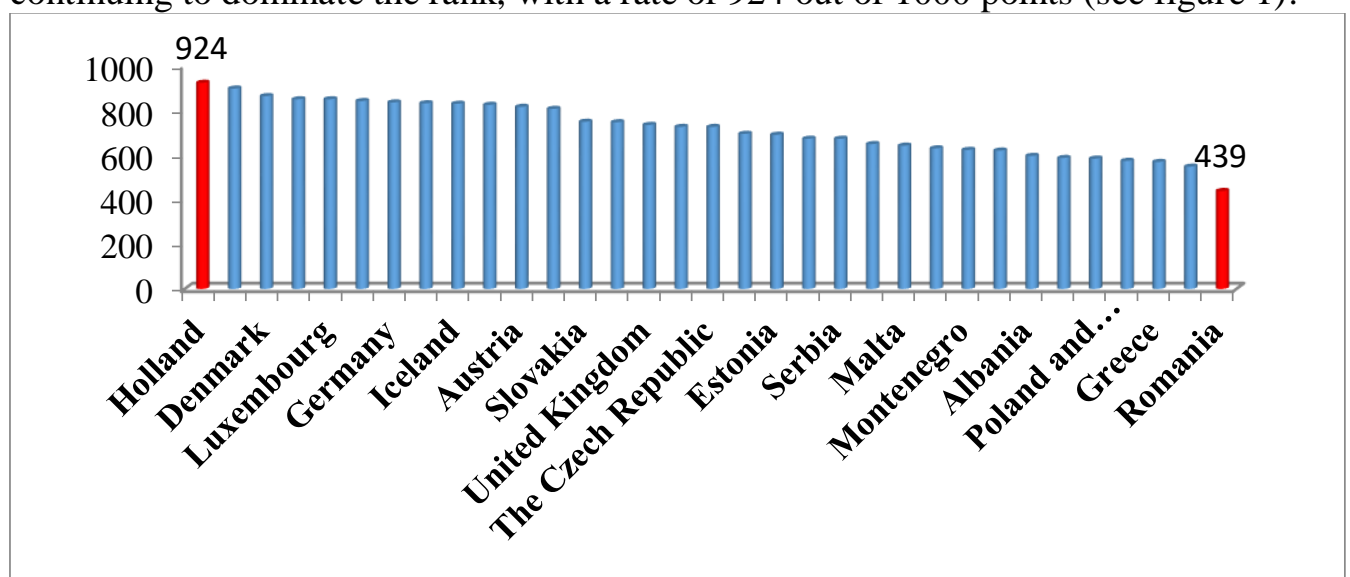

Figure 1. Romania's 2017 Euro Health Consumer Index score compared with the European countries. Source: adapted from Björnberg, A., 2016

For this indicator's computation, the following aspects have been examined: The possibility for patients to information's unconditionally access;

- $\quad$ Access to medical prescriptions; 
A Statistical Approach for Improving the Romanian Public Healthcare System Using the Lean Six Sigma Methodology

- $\quad$ Receiving qualitative medical prescriptions;

- $\quad$ Access to antibiotics, etc.

Romania's obtained result demonstrates an inferior level of the quality existing in the healthcare system, considering that, when the debate was made, the community from Health Consumer Powerhouse acknowledged that only the elementary existence of a medical system would bring the countries a rate of 333 points. Thus, Romania, related to other countries, has an unprivileged public healthcare system, evaluation resulted from listing the above-mentioned aspects, for which Romania was positioned on the last place.

Despite having high qualified doctors, in Romania the logistic status provided by the public healthcare system (like ancient medical apparatus, absence of funds, insecure buildings, etc) alters in a noticeable degree their work, ending with the massive migration of doctors and nurses towards various countries from European Union, that grant them to unravel the medical process in regular conditions (Juran\& Godfrey, 1999).

For gaining patients' confidence in sanitary organizations, Romania should reorganize its public healthcare system and implement an approach called Lean Six Sigma.

Lean Management approach proposes an integrated way of the system, yet with a diminished number of details, organizational formats and scientific tools for investigations, whilst the Six Sigma approach introduces a generic analytical structure for problems' solving as well as designing an organizational infrastructure, presenting however a diminished number of basic solutions. Thus, an optimal solution for the Romanian healthcare system would be to use both methodologies as a whole. The following aspects of the Lean Six Sigma approach would be monitored if applied to public health system:

$\checkmark$ A constitutional approach;

$\checkmark$ A projection built on performance. A project is seen as a constant dilemma, in need of a solution; a project approach is the only way for fixing the issues (Stamatis, 2011). Six Sigma strategies are used for general and complicated issues which involve strong scientific and statistical explanations, whilst Lean programs cover good practices, concentrating on achieving standard solutions;

$\checkmark$ Judicious organization of the resources. A competent process' control, standard operations, well defined aspects and obligations are needed in order to protect solutions' utilization and avoiding their dissipation;

$\checkmark$ Commuting strategic objectives in performance indexes and obtainable objectives (Hohmann, 2012).

When we refer to quality management, normally the assessment is made through a performance management structure. Essentially, at this stage, it is sanitary institutions'

DOI: 10.24818/18423264/52.3.18.04 
Ruxandra Dinulescu, Ion Smeureanu, Cosmin Dobrin, Ion Popa

turn to agree if the performance level is adequate or not. Assuming that the level is tolerable, then the healthcare institution pursues to measure this level for assuring that, with time, the measure will not reduce. Contrarily (for a decreased level), the medical institution should consider making an advancement step.

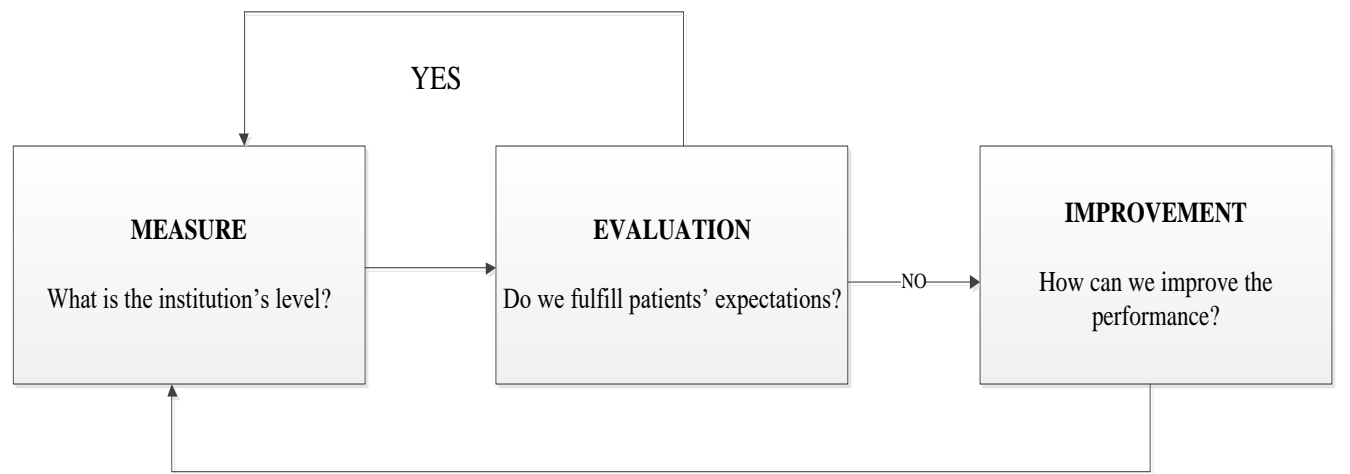

Figure 2. The performance management system

\section{Literature Review- Lean Six Sigma in the Romanian public healthcare system}

The public healthcare system still has a lot to accomplish before reaching a nondefective level (there are defects regarding the treatment, there are variations in patients' waiting time which lead to dissatisfaction, there is a waste of financial resources, etc.). Taking into account the above indications, Six Sigma is a fundamental approach for observing, evaluating and fixing variations (abounding) from an activity. This dilemma occurs due to the fact that each process owns its fluctuations (Patrice\&Spath, 2011), counting the medical procedures as well. Hence, a couple of internal issues and displeasures are developing from the patients' part, due to various fluctuations. In addition to this, Six Sigma presents a couple of instruments able to diminish the process's fluctuations.

Sadly, no medical process is escapes from defects' generating (Isaic-Maniu, 1995). In Six Sigma approach, the number of errors can be identified as quality criterion. Particularly, a so called "Six Sigma road map" is used for developing a certain level of quality. The following fundamentals steps:

1) Establishing the most critical practices and meaningful consumers;

2) Defining clients' needs;

3) Measuring the actual performance;

4) Analyzing and introducing improvements;

5) Achieving Six Sigma movement in the institution. 
A Statistical Approach for Improving the Romanian Public Healthcare System Using the Lean Six Sigma Methodology

After completing the third step, the number of errors that occur at every operation's step can be finally quoted. The possibility that an error could occur is represented as the sum of defects, explicated as a percentage. In our case, the Six Sigma methodology guides the hospital, to determine a standard for the maximal accepted probability that an error could occur (this activity is nominated as process variation).

However, as time passed by, the Lean Six Sigma approach displayed us that 99\% (meaning a level of 5 sigma) is insufficient. Nonetheless, for a public hearing a statement like this, the early inquiry would be: " $99 \%$ is a great percentage, yet why insufficient?"

Basically, an error rate of $1 \%$, corresponding to 5-sigma confidence, can still be relatively high when the total population is in the order of millions, and $1 \%$ of a million represents 10,000 , which is still a high number.

As an illustration, we will detail various reasons why $99 \%$ accomplishment is insufficient:

- In America approximately 4 million children are born every year. If the chance of leaving home with your own child would raise at $99 \%$, then this would have as a consequence that 4000 families would leave the maternity with the wrong child annually;

- For 14 million plastic surgeries with a fulfillment quota of 99\%, this would result in 14000 plastic surgeries inaccurate made;

- In America 15000 dentists graduate and assuming that we would have a fulfillment quota of $99 \%$, that would result in the fact that 15 of them don't manage well their activities (this condition could be elongated to every medical field, and for sure, the next rhetorical question would appear: who would want to be evaluated by them?).

As specified from the introduction, Six Sigma is an approach that pursues quality development, by diminishing errors along with their sources. The methodology focuses on those results which show an increased importance for customers, as well as, having the opportunity to convert their demands in perceptible requirements.

\section{Applied Methods}

\subsection{Prioritizing important activities for the patients - Priority calculator}

So that it can offer a high comfort level for its patients, the Romanian sanitary system could use a set of improvements. Thus, these activities don't offer the possibility to be accomplished in a short time, meaning that the establishment of an organization culture might be needed, which would target each problem.

For ensuring the above actions, we have decided to create a "priority calculator". Its main role is to show the primary directions that should be endorsed, as in the primary failures that need to be solved, and then arrange each one of them, taking into

DOI: $10.24818 / 18423264 / 52.3 .18 .04$ 
Ruxandra Dinulescu, Ion Smeureanu, Cosmin Dobrin, Ion Popa

consideration some indicators, following the preference order established by the patients.

Following the "priority calculator's" rules, each deficiency that requires a particular attention is identified as a project which possesses the following forms:

- A determined attention level for the customer;

- A determined imperative cost for application;

- A determined level of feasibility;

- An impact on people around the project.

Table 1 depicts this condition taking as example the case of a public Clinique from Bucharest:

Table1.Priority calculator in a public Clinique from Bucharest

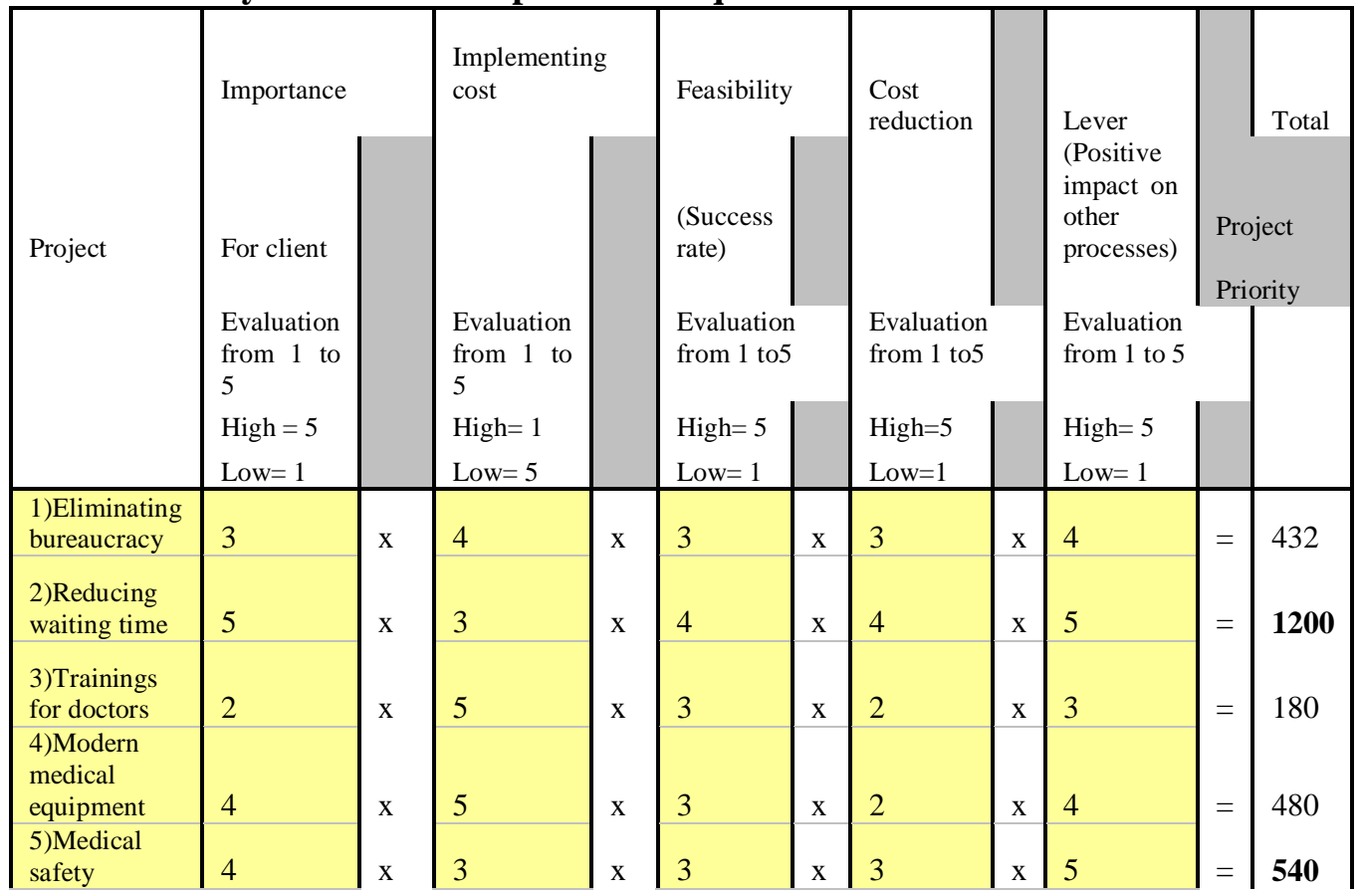

For generating the "calculator", five fundamental projects were selected, which in return, if accurately realized, would support implementing a higher development for the Romanian healthcare system. The above matrix was granted, found on inquiries made for patients and doctors answers from a public healthcare Romanian Clinique, a rate for every task, considering the five recorded features. So the rates were multiplied, achieving the so called "priority calculator". The prioritized task will be the one with the highest result. Thus, judging by the computations made, it can be easily observed 
A Statistical Approach for Improving the Romanian Public Healthcare System Using the Lean Six Sigma Methodology

that the tasks which demand special consideration are "diminishing the awaiting time in front of the medical cabinet", with a rate of 1200 , pursued by "medical safety" (here we can incorporate hospitals' sanitation, admission rooms, etc) with a rate of 540 points.

The main tool's aspect is to support activities with the highest probable advantage, for revealing an opening guidance in order to improve the clinics and hospitals from Romania.

Immediately after the "calculator" is created, the primary task has been revealed and so, based on this, an evaluation will be conducted, for better forecast the waiting time.

\subsection{Evaluating the patients' waiting time fluctuation}

Lean Six Sigma methodology uses as a primary theory the idea of removing the deviations from a process. Like so, the general approach is to mark the inputs with " $X$ " and the results, as in the outputs, with "Y". In this way, a Lean Six Sigma strategy intents to ease the perception between the variables that are represented as independent (the Xs) and the ones represented as dependent (Ys). Putting this procedure as a mathematical equation, and considering that $\mathrm{Y}$ would represent a function of $\mathrm{X}$, it would be reproduced in the following matter: $Y=f((X 1, X 2, \ldots . X n)$. The so called transfer function, specified above, has the capability to convert the process' inputs into outputs. In another way of presenting it, any deviation (or variability) in inputs will attract a sequence of errors (defects) in the outputs.

Basically, the main goal is to determine the Xs (inputs), to establish which inputs are essential, and then to evaluate the alliance between those inputs and outputs.

In the present, we can state that every process has its own deviation (variation). Each business field encounters a certain level of variation, with a higher or lower, depending on the industry (the term variation defines an alternate procedure, which doesn't show regular or constant parameters every time investigated; achieving a distinctive result compared to the one expected at a certain step in the procedure). Definitely, the healthcare system, together with other systems, shows level of variation in distinctive steps of the procedure, like: fluctuation in patients' waiting time, fluctuations regarding the treatments, etc.

The types of variations are the following (figure 3):

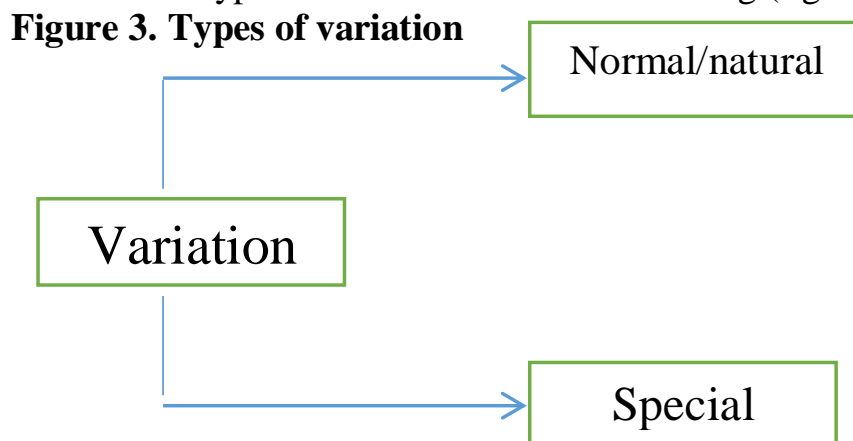

- Results from the factors outside the process;

- Minimum effect over the process's performance;

- Results from the process's regulated rhythm.

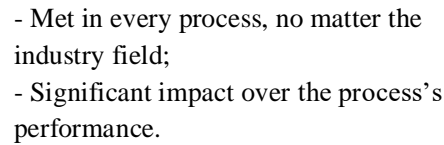

DOI: $10.24818 / 18423264 / 52.3 .18 .04$ 
Our situation will focus on the deviation (variation) existing in the patients' waiting time along the cabinets. Computing the waiting times' central tendency will show exclusively the data centering, and not the manner in which data are disseminated.

As a result, the dispersions' measure (variability) will be adopted. Per se, the mean could become a good representation of the observations if the values of dispersions' quotas illustrate the idea that the observations are focused around the mean.

One of the most important elements when referring to quality control is the level of variation, due to the fact that it has the possibility to engender a level of conformity according to standards, for the process production. Further, we can analyze the data spread in more than one distribution with the help of variability study. Presuming that the for the patients' waiting time the arithmetic calculated mean, for two medical cabinets, is 8 minutes, the first conclusion would be that the patients belonging to the both cabinets wait before the examination, about 8 minutes in front of the cabinets. Nonetheless, studying this action for a period of time, the results showed us that patients' first cabinet wait between 5 and 9 minutes until investigation, while patients' second cabinet wait between 4 and 20 minutes. So, the consequence results in the fact that the second cabinet demonstrates a decreasing level of efficiency comparing to the first cabinet.

In essence among the main adopted dispersion's measures we can enumerate the amplitude, the standard deviation and the variation. The easiest variability measure is the amplitude, and its way of computing is by subtracting the lowest value from the highest value from an observation set.

Even though the patients call for an appointment every time before arriving at the physician, there are moments when they are forced to wait for about 30 minutes more than the original appointment, before entering the cabinet.

This matter serves as a source of displeasure for the patients, reducing their trust in the public medical institutions.

So after the computations were made, the medium deviation value for all the 84 observations is 5.09. In this way, it can be affirmed that the delaying time for the 14 samples fluctuates (deviates) from the mean with 5.09.

One of the most used measures for variability is standard deviation. The lower the standard deviation is, the closer the observations will be from the mean. Based on the sample provided, as in 84 patients (taken from an amount of 104 patients), and considering also the highest upper control limit accepted by the patient, 15 minutes, we want to detect how many patients waited above that limit. Taking into consideration the computations resulted from the standard score ( $\mathrm{Z}$ score), the mean values $(8.10$ minutes) and the standard deviation (the distance of an observation from the mean), we will determine how many values are superior to the rate of 1.355 . 
A Statistical Approach for Improving the Romanian Public Healthcare System Using the Lean Six Sigma Methodology

$$
z=\frac{X_{i}-\mu}{\sigma}=\frac{15-8.1}{5.09}=1.355
$$

Before continuing with the calculations and results obtained, we will first present the demographics table below:

\section{Table 2. Demographic table}

\begin{tabular}{|c|c|c|c|c|c|c|c|c|c|}
\hline \multirow[b]{2}{*}{ Row Labels } & \multirow[b]{2}{*}{$\nabla$} & $0-15$ & & $16-30$ & & 30+ & & \multirow[t]{2}{*}{$\begin{array}{l}\text { Total \% of } \\
\text { Patients }\end{array}$} & \multirow[t]{2}{*}{$\begin{array}{l}\text { Total Average } \\
\text { of Waiting } \\
\text { time in front of } \\
\text { the cabinet } \\
\text { (min) }\end{array}$} \\
\hline & & $\%$ of Patients & $\begin{array}{l}\text { Average of } \\
\text { Waiting time } \\
\text { in front of the } \\
\text { cabinet (min) }\end{array}$ & $\%$ of Patients & $\begin{array}{l}\text { Average of } \\
\text { Waiting time in } \\
\text { front of the } \\
\text { cabinet (min) }\end{array}$ & $\begin{array}{l}\% \text { of } \\
\text { Patients }\end{array}$ & $\begin{array}{l}\text { Average of } \\
\text { Waiting time } \\
\text { in front of the } \\
\text { cabinet (min) }\end{array}$ & & \\
\hline$\boxminus$ Acute & & $25.00 \%$ & 8.81 & $9.52 \%$ & 5.38 & $13.10 \%$ & 7.73 & $47.62 \%$ & 7.83 \\
\hline$\Xi$ Referral to the specialist & & $\mathbf{5 . 9 5} \%$ & 5.40 & $2.38 \%$ & 2.50 & $4.76 \%$ & 9.50 & $13.10 \%$ & 6.36 \\
\hline Female & & $4.76 \%$ & 5.75 & $1.19 \%$ & 3.00 & $2.38 \%$ & 14.50 & $8.33 \%$ & 7.86 \\
\hline Male & & $1.19 \%$ & 4.00 & $1.19 \%$ & 2.00 & $2.38 \%$ & 4.50 & $4.76 \%$ & 3.75 \\
\hline$\Xi$ Treatment & & $19.05 \%$ & 9.88 & $7.14 \%$ & 6.33 & $8.33 \%$ & 6.71 & $34.52 \%$ & 8.38 \\
\hline Female & & $10.71 \%$ & 9.00 & $4.76 \%$ & 4.75 & $3.57 \%$ & 9.33 & $19.05 \%$ & 8.00 \\
\hline Male & & $8.33 \%$ & 11.00 & $2.38 \%$ & 9.50 & $4.76 \%$ & 4.75 & $15.48 \%$ & 8.85 \\
\hline Chronic & & $28.57 \%$ & 8.50 & $13.10 \%$ & 7.64 & $10.71 \%$ & 8.89 & $52.38 \%$ & 8.36 \\
\hline$\Xi$ Referral to the specialist & & $16.67 \%$ & 10.36 & $4.76 \%$ & 6.50 & $4.76 \%$ & 8.00 & $26.19 \%$ & 9.23 \\
\hline Female & & $7.14 \%$ & 10.83 & $1.19 \%$ & 7.00 & $2.38 \%$ & 10.00 & $10.71 \%$ & 10.22 \\
\hline Male & & $9.52 \%$ & 10.00 & $3.57 \%$ & 6.33 & $2.38 \%$ & 6.00 & $15.48 \%$ & 8.54 \\
\hline$\boxminus$ Treatment & & $11.90 \%$ & 5.90 & $8.33 \%$ & 8.29 & $5.95 \%$ & 9.60 & $26.19 \%$ & 7.50 \\
\hline Female & & $2.38 \%$ & 8.00 & $3.57 \%$ & 7.67 & $2.38 \%$ & 6.00 & $8.33 \%$ & 7.29 \\
\hline Male & & $9.52 \%$ & 5.38 & $4.76 \%$ & 8.75 & $3.57 \%$ & 12.00 & $17.86 \%$ & 7.60 \\
\hline Grand Total & & $53.57 \%$ & 8.64 & $22.62 \%$ & 6.68 & $23.81 \%$ & 8.25 & $100.00 \%$ & 8.11 \\
\hline
\end{tabular}

In the above table, we can observe our 84 samples and their demographic values, along with the average waiting time spend in front of the cabinet. From all 84 samples, $47.62 \%$ of them (both male and females, included in all the three categories of ages) came with an acute treatment, while $52.38 \%$ came with a chronic treatment. The differentiation regarding the waiting time, was also made according to the purpose of visit (it can be easily observed that, in most of the cases, the average waiting time for those who came for a referral to the specialist is lower than the average waiting time for those who came for a treatment).

\subsection{Estimating patients' waiting time as reported by the informational system's blocking period}

Next we will pay attention to a different statistical instrument which has the ability to confirm or infirm the relation between values (the blocking duration of the information system and delays in patients' time). The approach allows us to predict results based on input data. Linear regression is the easiest type of acknowledged

DOI: 10.24818/18423264/52.3.18.04 
Ruxandra Dinulescu, Ion Smeureanu, Cosmin Dobrin, Ion Popa

regression, but this time we will use a multiple (multifactor) regression. Linear relationships between two or more phenomena can also be studied using canonicalcorrelation analysis, the generalized version of bivariate correlation (Kettenring 1971) used in (Dârdală 2017).

When the value of another variable is already established, the above analysis will help us forecast the value of the unknown variable. Particularly, two types of variables will be mentioned, such as independent variables (for whom we know the value) and the dependent variable (for whom we want to determine the value, based on the already established variable).

The regression function will be the following:

$$
\mathrm{Y}=\mathrm{a}+\mathrm{bX}+\mathrm{c} \mathrm{X}_{2}+\varepsilon
$$

where:

- $\quad \mathrm{Y}=$ total patient's waiting time (dependent variable);

- $\mathrm{X}_{1}=$ consultation time (independent variable);

- $\mathrm{X}_{2}=$ information system downtime (independent variable);

- $\mathrm{a}=$ the intercept (constant term);

- $\mathrm{b}, \mathrm{c}=$ regression slope (shows how much $\mathrm{Y}$ modifies when $\mathrm{X}_{1}$, respectively $\mathrm{X}_{2}$ increases or decreases with one unit);

- $\varepsilon=$ residual term, capturing all non-regressor factors influence.

Basically, the regression shows how a variable is dependent on another variable, and the correlation shows the degree in which a variable is dependent on another variable (Montgomery, 2005).

\section{Methodology's results}

From a total of 84 persons it can be smoothly seen that $9.52 \%$ will encounter delays of at least 15 minutes before entering the cabinet. The main reason that caused delays in patients' waiting time is considered to be due to the blockages developed in the informatics structure (noting that Romanian clinics and hospitals still present failures regarding the informatics system). 
A Statistical Approach for Improving the Romanian Public Healthcare System Using the Lean Six Sigma Methodology

\section{Table 3.Patients' waiting time $Z$ score}

\begin{tabular}{|c|c|c|c|c|c|c|}
\hline \multirow[t]{14}{*}{$Z$ score } & -1.39446 & -0.02102 & -0.60964 & -0.80584 & 0.371389 & -0.60964 \\
\hline & -1.59067 & -0.21723 & -0.60964 & 0.371389 & -0.60964 & -0.60964 \\
\hline & -0.02102 & -0.41343 & -0.60964 & 0.371389 & -0.80584 & -0.60964 \\
\hline & 1.54862 & 2.92206 & -1.00205 & 0.175183 & -0.41343 & -0.41343 \\
\hline & 1.352416 & -0.60964 & -0.41343 & 0.175183 & -0.21723 & -0.02102 \\
\hline & -0.80584 & -0.60964 & -0.80584 & -0.21723 & -0.21723 & 0.175183 \\
\hline & -0.21723 & -0.60964 & 0.567594 & -0.41343 & 0.7638 & -0.21723 \\
\hline & -0.02102 & -1.00205 & 1.94103 & -0.60964 & 0.175183 & -1.00205 \\
\hline & -0.02102 & 1.54862 & -0.41343 & 0.567594 & 1.156211 & 0.371389 \\
\hline & 0.371389 & 2.33344 & 4.2955 & -1.00205 & 0.960005 & -0.60964 \\
\hline & 1.94103 & -0.21723 & -0.41343 & 1.156211 & 0.175183 & -0.80584 \\
\hline & 2.33344 & -0.80584 & -0.41343 & 0.960005 & -0.60964 & -0.80584 \\
\hline & -1.00205 & -0.41343 & -0.41343 & 0.371389 & -1.00205 & -0.21723 \\
\hline & 0.567594 & 0.175183 & -0.41343 & 0.371389 & -1.19825 & -0.41343 \\
\hline
\end{tabular}

$\begin{array}{lr}\text { Mean } & 8.1 \\ \text { Standard deviation } & 5.09\end{array}$

During the research, 84 values were showed during one week, presenting the patients' waiting times (in one week, 84 patients were randomly selected). Thus, by using Excel program, a regression analyze will be created, that will allow us to determine, conforming to the informatics system's blocking period and the consultation's duration (treated as independent variable, $\mathrm{X}$ ), how much variability exists in patients' waiting time (treated as dependent variable, Y).

Previously, it is mandatory to remark that a type of linear regression claims that the association between the independent and dependent variable to be linear (Yank\&ElHaik, 2003).

Considering that the correlation coefficient resulted, or Pearson coefficient (also calculated with Excel program and $=\operatorname{CORREL}(\mathrm{x}, \mathrm{y})$ function) was 0.902117 and the plot diagram assigned, a strong correlation between the 2 variables is demonstrated (patients' waiting time and informational system's blocking duration), concluding that there is an influence between the two variables (one variable influences the other). Beneath, the multifactor regression function resulted:

DOI: 10.24818/18423264/52.3.18.04 
Ruxandra Dinulescu, Ion Smeureanu, Cosmin Dobrin, Ion Popa

\begin{tabular}{lr}
\hline \hline \multicolumn{2}{c}{ Regression Statistics } \\
\hline Multiple R & 0.903990715 \\
R Square & 0.817199213 \\
Adjusted R Square & 0.812685614 \\
Standard Error & 2.205842479 \\
Observations & 84 \\
\hline
\end{tabular}

ANOVA

\begin{tabular}{|c|c|c|c|c|c|c|}
\hline & $d f$ & & SS & MS & $F$ & gnificance $F$ \\
\hline Regression & & 2 & 1761.91069 & 880.955 & 181.053 & $1.3 \mathrm{E}-30$ \\
\hline Residual & & 81 & 394.1250244 & 4.86574 & & \\
\hline Total & & 83 & 2156.035714 & & & \\
\hline
\end{tabular}

\begin{tabular}{|c|c|c|c|c|c|c|c|c|}
\hline & Coeffieients & Standard Error & tStat & P-value. & ower 95\% & Ipper 95\% & wer $95.0 \%$ & Upper $95.0 \%$ \\
\hline Intercept & 1.383700302 & 1.243175767 & 1.11304 & 0.26898 & -1.0898 & 3.85723 & -1.08983 & 3.85723012 \\
\hline $\begin{array}{l}\text { Consultation's duration } \\
\text { Informational system's }\end{array}$ & 0.107174558 & 0.087523803 & 1.22452 & 0.22431 & -0.067 & 0.28132 & -0.06697 & 0.28131947 \\
\hline blocking duration & 0.663453753 & 0.041089351 & 16.1466 & $4.8 \mathrm{E}-27$ & 0.5817 & 0.74521 & 0.581699 & 0.74520867 \\
\hline
\end{tabular}

The three correlation coefficients are: $a=1.38, b=0.1$ and $c=0.66$. Hence, the emerged function is:

$$
\mathrm{Y}=1.38+0.1 * \mathrm{X}_{1}+0.66 * \mathrm{X}_{2} \text {. }
$$

Obtaining the function above and recognizing the duration of the blockages in the informatics system (seen as variable X2), now we are allowed to forecast the time needed for patients to enter the cabinet (the value of the total waiting time).

Also, judging from the multiple $\mathrm{R}$ value we can conclude that is well chosen and the informational system's blocking duration as well as consultation's duration explain the variation of patients' waiting time in a proportion of $90.39 \%$.

For determining the correlation between the above mentioned variables, an additional action was used for which ANOVA analysis was adopted, respectively the hypothesis testing (Meyer, 2012)

The main two elaborated hypotheses were:

- H0 (the null hypothesis): the variation of patients' waiting time is not altered by the informatics system

- H1 (the accepted hypothesis): the patients' waiting time variation is altered by the informatics system

The table resulted from the ANOVA analysis table can be examined below: 
A Statistical Approach for Improving the Romanian Public Healthcare System Using the Lean Six Sigma Methodology

Anova: Single Factor

SUMMARY

\begin{tabular}{lrrrr}
\hline \multicolumn{1}{c}{ Groups } & Count & \multicolumn{1}{c}{ Sum } & Average & Variance \\
\hline Column 1 & 84 & 644 & 7.666667 & 44.75502 \\
Column 2 & 84 & 681 & 8.107143 & 25.97633 \\
\hline
\end{tabular}

ANOVA

\begin{tabular}{lrrrrr|r|r}
\hline Source of Variation & \multicolumn{1}{c}{$S S$} & $d f$ & \multicolumn{1}{c}{$M S$} & \multicolumn{1}{c}{ PS } & \multicolumn{1}{l}{ P-value } & F crit \\
\hline Between Groups & 8.14881 & 1 & 8.14881 & 0.230416 & 0.631848 & 3.898089 \\
Within Groups & 5870.702 & 166 & 35.36568 & & & \\
& & & & & & \\
Total & 5878.851 & 167 & & & & \\
\hline
\end{tabular}

Figure 5. ANOVA method output

The ANOVA analysis rejected the null hypothesis $\mathrm{H} 0$ at $95 \%$ confidence level $(\mathrm{F}=$ $0.23<$ F_crit $=3.89$ ).

Another confirmation for rejecting the null hypothesis comes also from the t-test below (conducted on the variables patients' waiting time and informatics system's blocking duration):

\begin{tabular}{lrr}
\hline & Variable 1 & Variable 2 \\
\hline Mean & 7.666666667 & 8.107143 \\
Variance & 44.75502008 & 25.97633 \\
Observations & 84 & 84 \\
Hypothesized Mean I & 0 & \\
df & 155 \\
t Stat & -0.480016422 \\
P $(T<=t)$ one-tail & 0.315946206 \\
t Critical one-tail & 1.654743774 \\
P $(T<=t)$ two-tail & 0.631892413 \\
t Critical two-tail & 1.975387131 & \\
\hline
\end{tabular}

Figure 6.t-Test: Two-Sample Assuming Unequal Variances

DOI: 10.24818/18423264/52.3.18.04 
Ruxandra Dinulescu, Ion Smeureanu, Cosmin Dobrin, Ion Popa

For our observations the obtained results showed us that the when comparing the t-value with t-critical two tail, the value from the first indicator (t-value) is smaller than the second indicator's value (t-critical), in which case the null hypothesis will be rejected.

To conclude, when there are two variables involved and we want to determine if a variable has an influence on another variable, for a Six Sigma approach, the most convenient method is a regression analysis (Dinulescu, 2015). Thereby, taking into consideration the events resulted, we were able to measure the delays in patients' waiting time before entering the cabinet (considering that no emergency interfered at that time) when the informatics system had blockages within 1 and 30 minutes.

The first component of waiting time (consultation itself) is normal distributed around a seven-minute average, due to the homogeneity of the treated cases in a cabinet.

The second component, downtime of information system, has more reasons that are technical.

Hospital information system also manages clinical equipment including dedicated computers, a wide range of patient monitors, tomographs, EKG/ECG machines, wear sensors etc. and manifest a tight dependence of communication infrastructure (to integrate different laboratories or to connect national or private insurance companies).

In order to observe the frequency of the information system blockages, the phenomenon was monitored over a period of about six months; the data has been completed with the log events files from the operating systems of the computers.

From the communications point of view for the tested sample, the most important issue was connecting to the CASMB website, for validating the health card and granting free compensation to recipes.

The short-term mitigation solution consists of collecting applications on the local computer and sending them for batch processing, on the same day, the calendar date being a critical element in the provision of medication as well as in the validation of medical discharge or other rights.

The long-term solution consists of software update and real communication infrastructure improvements.

For the second component time, Weibull distribution was tested because it gives the distribution of lifetime of objects, including fatigue state due to the usage; it modulates also the functionality of systems depending of a "weakest link" or poor connection.

In the same time, Weibull distribution is very versatile one, approaching the characteristics of other distributions, depending on the shape parameter value (Figure 7). 
A Statistical Approach for Improving the Romanian Public Healthcare System Using the Lean Six Sigma Methodology

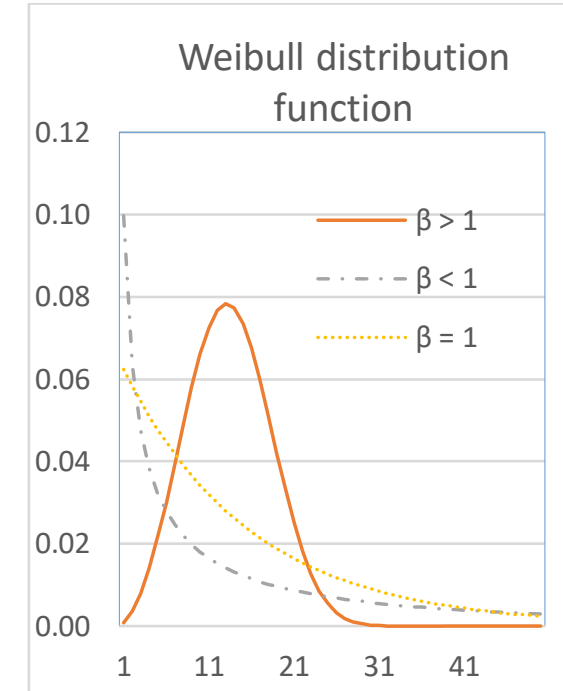

Figure 7.Weibull distribution shape for $\beta=3, \beta=0.5$ and $\beta=1$ (probability density function)

Indeed, acquired data is showing an increasing hazard function and Chi square statistics confirm us that information system failures follow a Weibull distribution:

$$
f(t)=\frac{\beta}{\eta}\left(\frac{t-\gamma}{\eta}\right)^{\beta-1} e^{-\left(\frac{t-\gamma}{\eta}\right)^{\beta}} ; \mathrm{t}>0 .
$$

Due to the big number of failures, we had to work under assumptions of repaired data using pattern of times between failures.

The estimated parameters we obtained are:

- $\quad \boldsymbol{\beta}=\mathbf{2 . 6}$ - shape (slope) parameter, reflect an intense use process, a long continuous running time, or sometimes a high wear-out rate;

- $\quad \boldsymbol{\beta}<1$, the failure rate decreases with time, denoting the presence of a large number of early-life failures and a stabilizing process in time;

- $\boldsymbol{\beta}=1$, the failure rate is constant, which means failures are almost uniform distributed in time;

- $\boldsymbol{\beta}>1$, the failure rate increases with time (it models wear-out failures, appearing after some time of usage or a long uninterrupted uptime operation;

- $\quad \gamma=\mathbf{3 3 7}$ minutes - location parameter, or failure-free time, when failures come after a while; it is also called the time parameter and is not included in the two parameter version of Weibull distribution;

DOI: 10.24818/18423264/52.3.18.04 
- $\boldsymbol{\eta}=\mathbf{1 5 \%}$, - scale parameter, or characteristic life parameter, the value in time when $15 \%$ of all failures will have occurred.

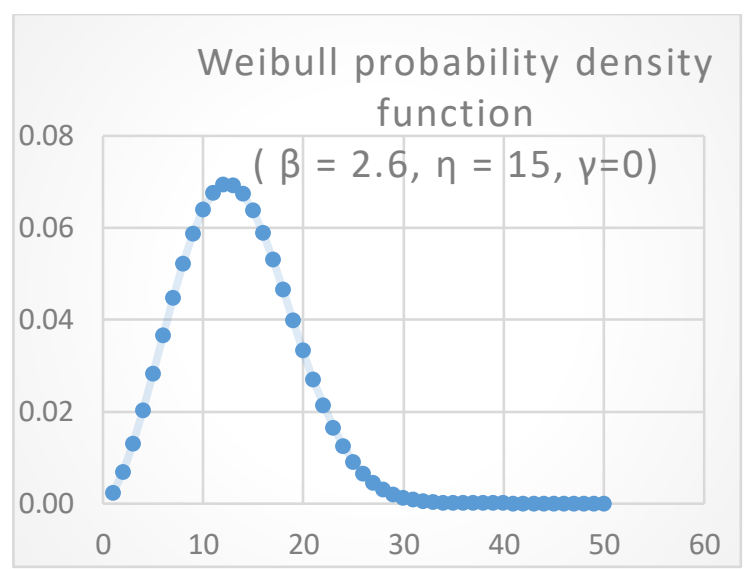

Figure 8. Weibull distribution for hospital information system failures ( $\beta$

$$
=2.6, \eta=15, \gamma=0 \text { ) }
$$

\section{Conclusions}

According to the results obtained above, the conclusion achieved is that the informatics system has an influence over the delays in patients' waiting time before entering the cabinet. Thus, the waiting time duration changes directly proportional with the information system's blocking duration - for example, if the blocking duration increases, the delays before entering the cabinet will increase as well.

Therefore, as a general solution, the ideal situation would be that the blocking in informational system would not last more than 3 minutes. In this way, the average waiting time in front of the medical cabinet would not be more than 5 minutes.

Although the analysis was made on a small dataset from one general practitioner (GP) cabinet, future studies should analyze differences in waiting time across different GP practices or even hospital departments.

With the help of Lean Six Sigma instruments the Romanian public health system could extent to a superior performance regarding the quality level. For decreasing the number of inefficiencies from the public healthcare system and also the processes' variation level, the two approaches need to be connected.

The methodologies' main objective is that in the end, the patient gains confidence regarding the process and adjusts the basic impression concerning the inferior level of quality from the healthcare system. Practically, the Lean approach serves as a management system as well as a philosophy, taking into consideration the magnitude, 
A Statistical Approach for Improving the Romanian Public Healthcare System Using the Lean Six Sigma Methodology

organization's development level and strategy, and also the culture where is administered.

Choosing the most convenient tool at the proper place and moment, result in eliminating or diminishing losses (Webber\&Wallace, 2007).

Judging by the ongoing research, designed for investigating a part of the advantages delivered by Lean Six Sigma instruments and likely suitable for the Romanian healthcare system, it can be stated that for building a healthcare system where quality is presented and also centered on patients' requirements, the following aspects should be targeted:

A person able to sustain the improvement and efficiency action, or a leader in that field, must manage the improvement process;

Putting the focus on patients' needs is as essential as in any other domain. In order to increase the patients' achievements, the Romanian healthcare system must assure an additional level of quality with reference to the provided sanitary services;

A comparative analyze could be convenient (Dobrin et al., 2017). Although in Bucharest there are many physicians working in public hospitals, and also in private medical institutions (working part-time), hence they have the probability to analyze the conditions related to the efficiency level as well as the qualitative level found in the private health system, in comparison to the public health system. Unfortunately, in the public healthcare system there is no program which could grant leaders and doctors to profit from an "experience exchange" at hospitals and clinics other than the Romanian area, where Lean Six Sigma approach is used, for better observing the adjustment degree as well as the innovations delivered by this. This action could be useful for noticing changes and habits currently delivered by Six Sigma hospitals, hence developing physician's trust in Lean Six Sigma.

All the employees should be involved in the developing process. From the moment when a hospital will initiate a Six Sigma approach, the implementation's team obligation is to advise the employees about Lean Six Sigma methodology, to get them used with the methodology's concepts, and above all, to indicate them that all improvements are possible by having their dedication and support. The aim is that the hospital's employees to know that they are allowed to commit any time to the development practices, and that their opinions will be accepted and welcomed by managers.

All in all, one thing is certain: the Romanian public health system needs further improvements. Even if there is a great potential from the part of the public healthcare system, without an appropriate guidance, this could continue to be just a system blamed by patients and bypassed the young doctors.

DOI: 10.24818/18423264/52.3.18.04 
Ruxandra Dinulescu, Ion Smeureanu, Cosmin Dobrin, Ion Popa

\section{REFERENCES}

[1] Bass I. (2007), Six Sigma Statistics with Excel and Minitab; McGraw-Hill Companies, USA;

[2] Björnberg, A. Euro Health Consumer Index 2016 Report. Available online: https://healthpowerhouse.com/files/EHCI-2017/EHCI-2017-report.pdf (accessed on 20 February 2018);

[3] Dârdală, M.; Furtună, T.F.; Ioniță, C. (2017), Statistical Methods for Analyzing the Relationship among Ethnic, Religious and Linguistic Diversity in Romania, pp. 37-54, Economic Computation and Economic Cybernetics Studies and Research; ASE Publishing, vol. 51, no. 4, 2017;

[4] Dinulescu, R.(2015), Romanian Public Health System Seen through the Eyes of Lean Method. In Proceedings of 26th IBIMA Conference on Innovation management and sustainable economic competitive advantage: from regional development to global growth, Madrid, Spain, 11-12 November 2015; pp. 125-131;

https://apps.webofknowledge.com/full_record.do?product=WOS\&search_mode=Gene ralSearch\&qid $=6 \&$ SID $=$ E3CMZleoFG8fb1o4kcg\&page $=1 \&$ doc $=1$;

[5] Dobrin, C.; Deac, V.; Dinulescu, R.(2017), Introduction to the Qualitative Analysis of the Romanian Healthcare System, pg.13, Quality - Access to success http://www.srac.ro/calitatea/arhiva/2017/2017-05-Cuprins.pdf , vol.18, nr.160, October 2017 ;

[6] George, M.O. (2010), The Lean Six Sigma Guide to Doing more with Less-Cut Costs, Reduce Waste and Lower your Overhead; John Wiley \& Sons, Inc, New Jersey; [7] Hohmann, C. (2012), Lean Management; Ed. Groupe Eyrolles, Paris;

[8] Isaic-Maniu, A. (1995), Statistica pentru managementul afacerilor; Economica Publishing; Bucharest;

[9] Juran ,J. \& Godfrey A. (1999), Juran's Quality Handbook; McGraw-Hill, USA;

[10] Kettenring, R.J. (1971), Canonical Analysis of Several Sets of Variables;

Biometrica, vol. 58, No. 3, pp. 433-451, 1971;

[11] Meyer, F. (2012), La revolution Lean Six Sigma dans les services; Ed. Lexitis, Paris;

[12] Montgomery, D. (2005), Introduction to Statistical Quality Control, 5th ed., Hoboken, NJ:Wiley;

[13] Patrice, I. Spath (2011), Error Reduction in Health Care. A Systems Approach to Improving Patient Safety, 2nd edition, Jossey-Bass, San Francisco; [14] Stamatis, D.H. (2011), Essentials for the Improvement of Healthcare Using Lean\&Six Sigma; CRC Press, New York;

[15] Webber, L. \& Wallace M. (2007), Quality Control for Dummies; Wiley

Publishing Inc, USA;

[16] Yang, K. \& El-Haik B. (2003), Design for Six Sigma; McGraw-Hill, New York. 